\begin{tabular}{|c|c|c|}
\hline \multirow{3}{*}{$\begin{array}{r}\text { Case Reports in } \\
\text { Gastroenterology }\end{array}$} & \multirow{2}{*}{\multicolumn{2}{|c|}{ Case Rep Gastroenterol 2014;8:324-328 }} \\
\hline & & \\
\hline & $\begin{array}{l}\text { DOI: 10.1159/000367591 } \\
\text { Publisned online: October 17, } 2014\end{array}$ & $\begin{array}{l}\text { ○ } 2014 \text { S. Karger AG, Basel } \\
\text { 1662-0631/14/0083-0324\$39.50/0 } \\
\text { www.karger.com/crg }\end{array}$ \\
\hline & \multicolumn{2}{|c|}{$\begin{array}{l}\text { This is an Open Access article licensed under the terms of the Creative Commons } \\
\text { Attribution-NonCommercial } 3.0 \text { Unported license (CC BY-NC) (www.karger.com/OA- } \\
\text { license), applicable to the online version of the article only. Distribution permitted for non- } \\
\text { commercial purposes only. }\end{array}$} \\
\hline
\end{tabular}

\title{
Arteriovenous Malformation Detected by Small Bowel Endoscopy
}

\author{
Takaaki Fujii Hiroki Morita Toshinaga Sutoh Takahiro Takada \\ Soichi Tsutsumi Hiroyuki Kuwano \\ Department of General Surgical Science, Gunma University Graduate School of Medicine, \\ Maebashi, Japan
}

\section{Key Words}

Arteriovenous malformation · Small bowel endoscopy

\begin{abstract}
Gastrointestinal bleeding that originates in the small intestine is often difficult to diagnose. When successful diagnosis reveals a lesion that can be localized preoperatively, the laparoscopic approach is an appropriate and beneficial treatment modality for small bowel resection. A 69-year-old man presented with a 6-month history of gastrointestinal bleeding and symptomatic transfusion-dependent anemia. Upper and lower endoscopy were normal. Double-balloon endoscopy established the source of the bleeding as a $0.5-\mathrm{cm}$ polypoid mass appearing as a submucosal tumor with redness and pulsation in the lower ileum, suggesting a vascular lesion. Laparoscopic small bowel resection was successful in removing the mass in the ileum. Histological evaluation of the mass revealed an arteriovenous malformation. Preoperative small bowel endoscopy can be useful for diagnosing the cause and localization of arteriovenous malformation in the small intestine.

(C) 2014 S. Karger AG, Basel
\end{abstract}

\section{Introduction}

Gastrointestinal bleeding that originates in the small intestine is often difficult to diagnose. Vascular lesions of the small intestine are common causes of gastrointestinal hemorrhage. Arteriovenous malformations (AVMs) are an important vascular cause of gastrointestinal bleeding. An AVM is most often located in the cecum and right side of the colon; however, AVMs of the small intestine are rare. It can be exceedingly difficult to localize and diagnose gastrointestinal tract bleeding, particularly in cases of occult small bowel AVMs [15]. Angiography and enhanced computed tomography (CT) are very useful and convenient 
Fujii et al.: Arteriovenous Malformation Detected by Small Bowel Endoscopy

for the detection of gastrointestinal AVMs [1-5]. Moreover, double-balloon endoscopy or capsule endoscopy would be also useful in the diagnosis of AVMs in the small bowel. We report the case of a 69-year-old man who presented with intestinal bleeding with anemia resulting from a small bowel AVM which was detected by double-balloon endoscopy.

\section{Case Report}

A 69-year-old man presented with a 6-month history of gastrointestinal bleeding and symptomatic transfusion-dependent anemia. Upper and lower endoscopy were normal and failed to confirm the bleeding site. Thus, he was referred to our hospital for the purpose of intensive examination and treatment. His vital signs were stable at admission. His laboratory data showed a hemoglobin of $7.8 \mathrm{~g} / \mathrm{dl}$. He had renal dysfunction due to diabetes, but no prior history of tarry stool. Abdominal CT did not detect the cause of bleeding (fig. 1). Because of renal dysfunction, contrast-enhanced CT and angiography were not performed. Capsule endoscopy examination revealed oozing of blood in the ileum, however a significant lesion was not detected. Double-balloon endoscopy established the source of the bleeding as a $0.5-\mathrm{cm}$ polypoid mass appearing as a submucosal tumor with redness and pulsation in the lower ileum (fig. 2). The polypoid mass was detected about $10 \mathrm{~cm}$ orally from the ileocecal valve by contrast radiography (fig. 3). Laparoscopic small bowel resection was successful in removing the mass in the ileum. The mass was located in the ileum $10 \mathrm{~cm}$ orally from the ileocecal valve. Histological evaluation revealed the polypoid mass to be showing an intact mucosal cover and numerous abnormal vessels in the underlying submucosa. These findings were compatible with AVM (fig. 4). The abnormal vessels penetrated the lamina muscularis and were considered the source of bleeding. Our follow-up of the patient has remained uneventful for 3 years.

\section{Discussion}

Gastrointestinal bleeding that originates in the small intestine is often difficult to diagnose [1-5]. When successful diagnosis reveals a lesion that can be localized preoperatively, the laparoscopic approach is an appropriate and beneficial treatment modality for small bowel resection [4]. We here report a case of AVM detected preoperatively by small bowel endoscopy. Preoperative localization of the small bowel lesion allowed minimally invasive treatment. AVM of the small bowel is rare, and whether endoscopic appearances are distinctive enough to raise the possibility of a polypoid AVM remains unclear [1, 4]. In our case, the mass resembled a submucosal tumor and the tumor had redness and pulsation, suggesting a vascular lesion (fig. 3). Awareness of the differential diagnosis of AVM might allow proper management and diagnosis. Preoperative small bowel endoscopy can be useful for diagnosing the cause and localization of AVM in the small intestine. This examination can be accomplished using minimally invasive laparoscopic small bowel resection.

\section{Acknowledgements}

The authors would like to thank Y. Saitoh, T. Yano, Y. Matsui, A. Ishida and A. Ishikubo for secretarial assistance. 
Fujii et al.: Arteriovenous Malformation Detected by Small Bowel Endoscopy

\section{Disclosure Statement}

The authors declare that they have no competing financial interests.

\section{References}

1 Endo H, Matsuhashi N, Inamori M, Ohya T, Yanagawa T, Asayama M, Hisatomi K, Teratani T, Fujita K, Yoneda M, Nakajima A: Tumorous arteriovenous malformation in the jejunum missed by capsule endoscopy. Gastrointest Endosc 2008;68:773-774; discussion 774.

-2 Rizvi AZ, Kaufman JA, Smith P, Silen ML: Solitary arteriovenous malformation of the small intestine. J Am Coll Surg 2005;200:808-809.

-3 Stauffer JA, Shaddix KK, Achem SR, Stark M, Adelson A, Metzger PP, Landmann RG: Intra-operative use of super-selective or highly selective angiography with methylene blue injection to localize arterial-venous malformation. Colorectal Dis 2011;13:e65-e66.

4 Takeshita N, Otsuka Y, Nara S, Noie T, Ito K, Harihara Y, Furushima K, Konishi T: Utility of preoperative small-bowel endoscopy for hemorrhagic lesions in the small intestine. Surg Today 2012;42:536-541.

-5 Nakabayashi T, Kudo M, Hirasawa T, Kuwano H: Arteriovenous malformation of the jejunum detected by arterial-phase enhanced helical CT, a case report. Hepatogastroenterology 2004;51:1066-1068.

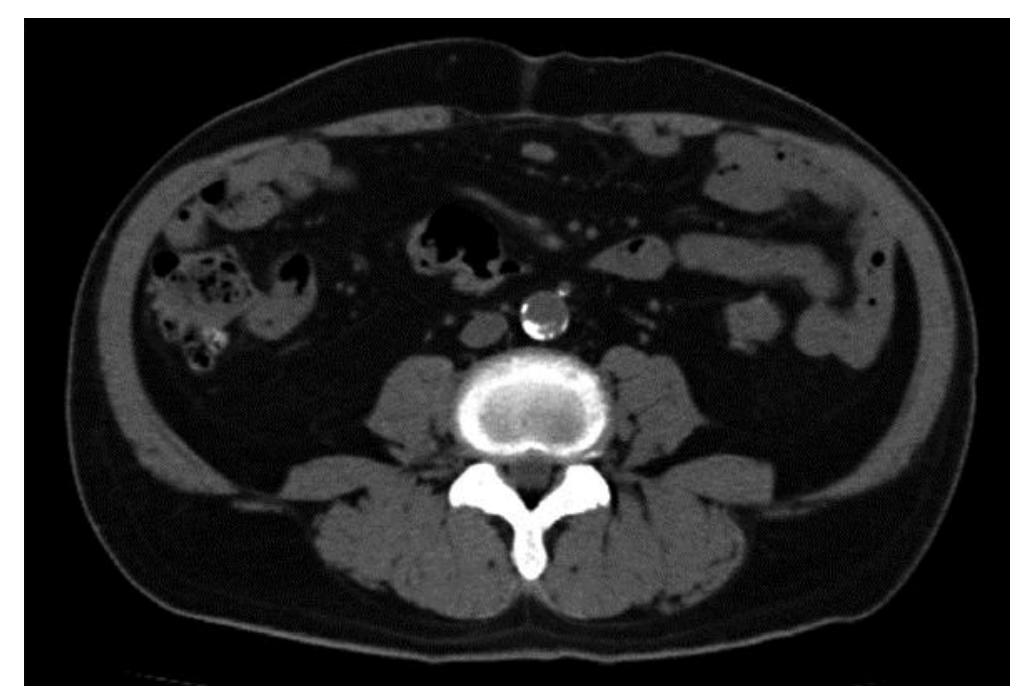

Fig. 1. Abdominal CT did not detect the cause of bleeding. 
DOI: $10.1159 / 000367591$

Fujii et al.: Arteriovenous Malformation Detected by Small Bowel Endoscopy

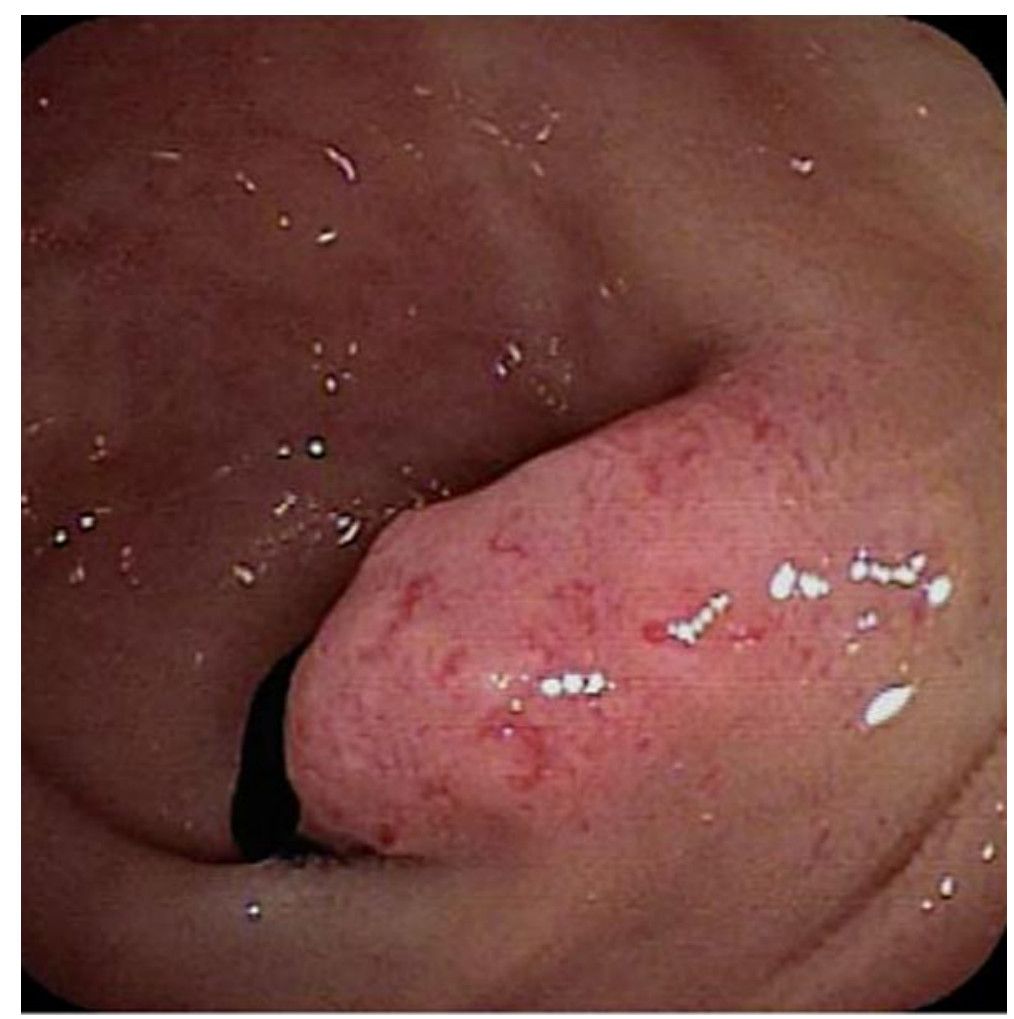

Fig. 2. Double-balloon endoscopy established the source of the bleeding as a 0.5 -cm polypoid mass appearing as a submucosal tumor with redness and pulsation in the lower ileum. 
Fujii et al.: Arteriovenous Malformation Detected by Small Bowel Endoscopy

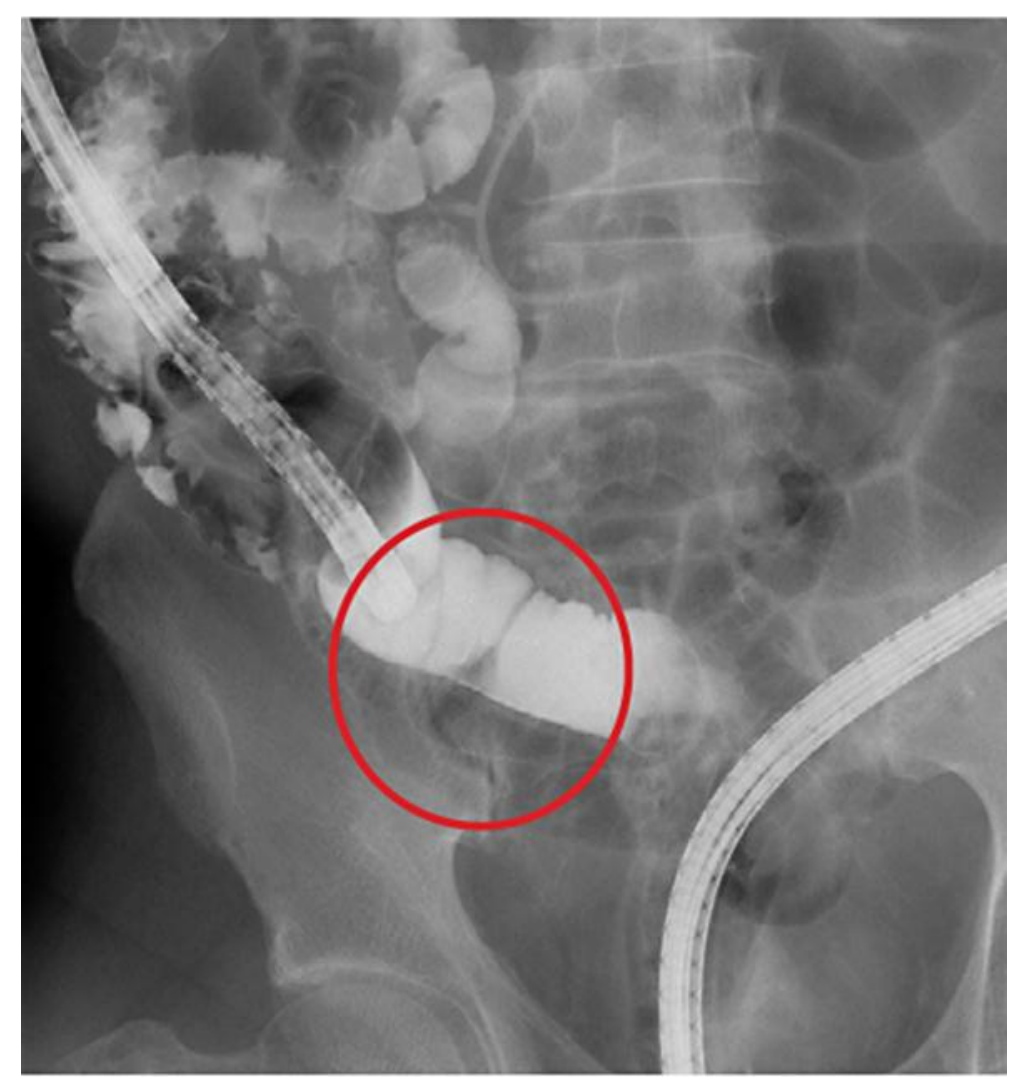

Fig. 3. The polypoid mass was detected about $10 \mathrm{~cm}$ orally from the ileocecal valve by contrast radiography.

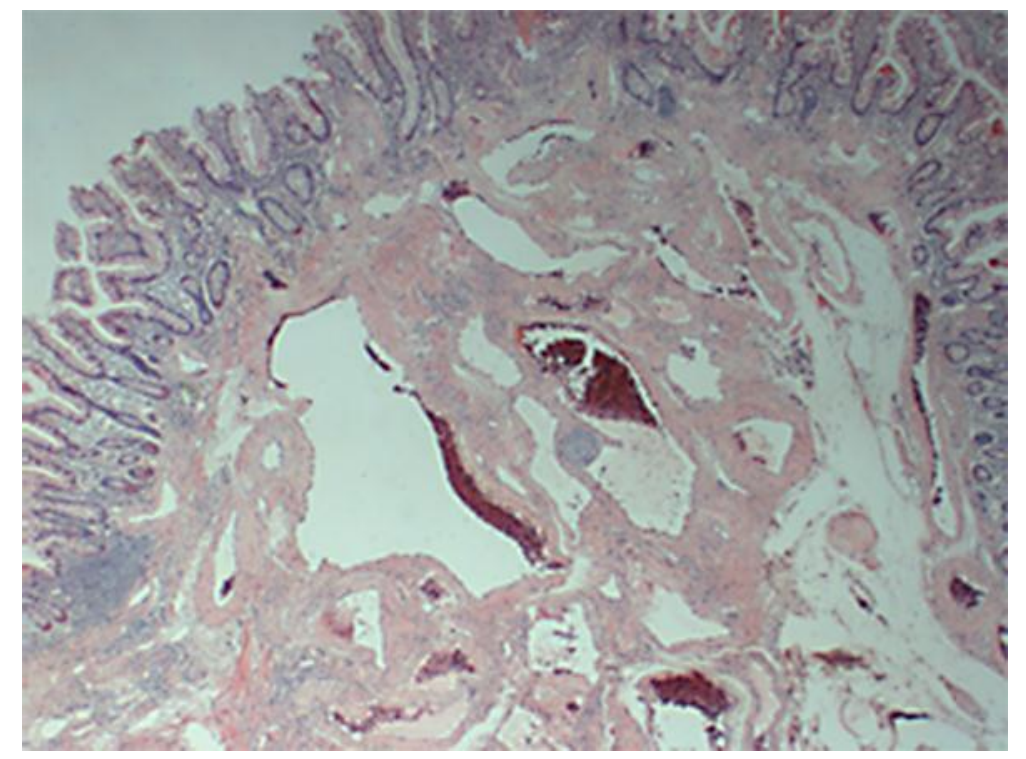

Fig. 4. Histological evaluation revealed the polypoid mass to be showing an intact mucosal cover and numerous abnormal vessels in the underlying submucosa. These findings were compatible with AVM. 